\title{
Value migration: digitalization of shipping as a mechanism of industry dethronement
}

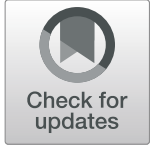

\author{
Konstantinos Poulis ${ }^{1 *}$, Gregorios C. Galanakis ${ }^{2}$, Gregory T. Triantafillou ${ }^{3}$ and Efthimios Poulis ${ }^{2}$
}

\author{
* Correspondence: poulisk@hotmail. \\ com \\ ${ }^{1}$ Middlesex University, London, UK \\ Full list of author information is \\ available at the end of the article
}

\begin{abstract}
In this conceptual paper, we review latest developments related to unmanned vessels and sketch potential scenarios that implicate with the existing maritime industry structure. On the one hand, we isolate a range of challenges that make the imminent realization of unmanned vessels seem like a rather utopian pursuit. On the other hand, we explain the reasons that may catalyse their emergence. Inspired by these opposing tensions, we highlight that the digital transformation of the shipping industry has the potential to enhance value within the industry's ecosystem. However, we also contend that unmanned vessels -if realized- pose a very particular threat to the identity of the shipping industry as we know it. In particular, we build upon the concept of value migration and we highlight the drastic existential changes that may likely stem from a shift to non-seafarer-centric shipping. We conclude with questions that matter for industry dethronement purposes i.e., the possibility that existing industry structures may be substantially reconfigured following a removal of the seafarer as the nucleus of value creation in shipping.

Keywords: Unmanned vessels, Crew, Value migration, Digitalization, Industry dethronement, Autonomous operations
\end{abstract}

\section{Introduction}

The historical shift from a less to a more technologically sophisticated regime (e.g. from the steam to the electronically-controlled diesel engine) is a testament to the abilities of incumbent shipping firms and of wider shipping stakeholders to navigate through the clutter of a fast-changing and utterly complex landscape (Ghaderi 2019; Lambrou et al. 2019; Mlimbila and Mbamba 2018). As a result, the shipping world has accumulated a certain sense of familiarity with ceaseless change and uncertainty. Nevertheless, the current digital transformation of the shipping industry is highly idiosyncratic and renders past experiences less fitting as means to address forthcoming challenges. This transformation has already challenged many shipping stakeholders' abilities e.g. see time lags in embracing innovation advances in ports (Vanelslander et al. 2019), issues of tackling cyber security threats (Fruth and Teuteberg 2017) or appropriation of big data (Yang et al. 2019). Therefore, we argue that such novel technological tendencies require constant revisiting and alertness. Otherwise, the purported benefits will remain misappropriated or unobserved.

(c) The Author(s). 2020 Open Access This article is licensed under a Creative Commons Attribution 4.0 International License, which permits use, sharing, adaptation, distribution and reproduction in any medium or format, as long as you give appropriate credit to the original author(s) and the source, provide a link to the Creative Commons licence, and indicate if changes were made. The images or other third party material in this article are included in the article's Creative Commons licence, unless indicated otherwise in a credit line to the material. If material is not included in the article's Creative Commons licence and your intended use is not permitted by statutory regulation or exceeds the permitted use, you will need to obtain permission directly from the copyright holder. To view a copy of this licence, visit http://creativecommons.org/licenses/by/4.0/. 
In this paper, these tendencies relate to unmanned vessels (henceforth called UV). We review advances in the relevant scholarship and we integrate them with the concept of value migration. This integration allows us to discuss the industry-level implications that such innovation will generate. Such a scenario approach that focuses on the longterm implications stemming from automation is highly valuable (see Milakis 2019; Lochner et al. 2018). Specifically, we indicate the existential implications that an assumed realization of UV will pose for incumbent players (shipowners) and consequently, for the industry as a whole. We argue that a move to non-seafarer-centric shipping will deprive traditional firms from one of its core competences and will allow migration of value to other, currently non-shipping fields. Hence, the potential scenarios that we illustrate are not a peripheral concern but rather ones that touch upon core identity themes that characterize shipping since its inception.

\section{Literature review}

Our literature review aims to introduce the topic of UV and its industry-level implications. We frame the section under two broad headings: factors impeding and factors enabling the realization of UV. In this way, we do not portray either scenario as more probable than the other since both may be equally promoted depending on one's assumptions. Therefore, we seek to offer a balanced perspective since no one can safely claim whether an unmanned future is feasible at this stage. Whether UV will eventually become a reality is not only related to technological developments (i.e., whether UV can be built) but also encompasses other concerns, too such as regulatory or societal ones. We try to clarify these nuances below. However, before doing so, we need to stress two overarching caveats as major assumptions and axiomatic beliefs in relation to our rationale. ${ }^{1}$ These caveats are important since this work is simply an opinion piece of work without any data to support any of the arguments:

- The first caveat is our belief that crew on board is a substantial source of value creation for a shipping firm (please see section on value creation below). As Progoulaki and Theotokas (2016) indicate, managing human resources on board is a sustainable source of competitive advantage that explains performance variations across shipping companies. Other studies have also pinpointed the human element as one of the major forces dictating the competitiveness of a maritime nation or of an individual shipping company (see Lee et al. 2014; Kuo et al. 2017). One of the reasons that explains this centrality of human resources is that the complexity of marine tasks (e.g. navigation) is heavily dependent on human skills. Certainly though, developments such as ECDIS gradually make 'raw' human skills less relevant than before. Therefore, if the advanced technological functions of an unmanned vessel can 'absorb' this complexity better than humans, this value will be lost and crew will be transformed into a 'value-less' element. This is the source of our arguments about the future implications stemming from a possible realization of UV.

- The second caveat is that UV will initiate structural changes in the industry as we know it i.e., they will enable the entry of non-traditional players (see below).

${ }^{1}$ We are grateful to one of the reviewers for this remark 
Currently, this threat is minimised due to high barriers to entry e.g. due to the capital- and knowledge-intensive nature of our industry. Nevertheless, we do not imply that a potential entry of non-traditional players will be better or worse for the industry or society at large. We remain 'agnostic' about this aspect since our role as authors of a journal paper is not to argue in favor of or against someone who may wish to create value or reap benefits out of shipping activity; or if retailing giants or forwarding companies should invest in the maritime industry following a vertical integration strategy. Shipping is a free and competitive market like other markets. As such, there are no inherent barriers to entry. Therefore, we note that our goal is solely to highlight the implications for the current industry structure stemming from a possible UV emergence. Whether such a shift will be beneficial to the final consumer, to the ship owner, to international trade or to society at large is an empirical question that can be answered only through further, ongoing research (since currently, comparative data are simply inexistent).

Having clarified these two caveats, we proceed with the factors that impede or enable the realization of UV.

\section{Factors impeding the realization of UV}

There are several UV projects under development (see Naeem and Irwin 2010; Porathe 2014; Burmeister et al. 2014). We are not interested in detailing their technical characteristics. Rather, in this section, we highlight reasons that make UV emergence an unlikely scenario since changes implicate with core features of the shipping industry.

1. The projects are mostly navigation-oriented and limited data exist on e.g. mooring and cargo operations at ports (Huntsberger et al. 2011). Moreover, a series of assumptions (e.g. 'bulk carrier only'; Rødseth and Burmeister 2015) implies a fragmented treatment that moves us away from a holistic understanding of UVs' operational feasibility (Hogg and Ghosh 2016).

2. Developers have publicized unconvincing results on financial implications. For example, there is an isolated reference to a 7 million present value gain in 25 years (unmanned-ship.org; MUNIN project) while independent researchers indicate a number of savings around 4.3 million USD (Kretschmann et al. 2017). A main reason for the 'legitimacy' of UV is the economic value for shipowning companies (e.g. savings from minimized crew costs). However, this is based on a series of assumptions, which ignore other unavoidable cost elements. For example, there is no factoring of costs for the personnel who will monitor operations from a shorebased control centre or the expenses of buying, upgrading and maintaining the arguably costly monitoring equipment and shore-based infrastructure (let alone newbuilding, land services or port-related costs).

3. There is no survey among stakeholders (e.g., shipowners, flag states, maritime institutional bodies) so as to surmise their disruptive susceptibility and the extent to which incumbents are willing to embrace UV (see D'Agostini et al. 2017 for an exception concerning seafarers). However, such a shared consensus is vital in a traditional industry where sources of accidents and consequences of failures vary 
dramatically (see Wróbel et al. 2017). Every innovation is supposed to serve the evolving needs of a core clientele; it does not have an a priori, intrinsic value. When the value of an innovation is eventually judged by its prospective users, how can one surmise the value-adding benefits of UV without those users' opinion?

4. There is also a parsimonious representation of regulatory challenges associated with UV. Nevertheless, these are not issues of minor concern when it comes to digitalisation in shipping. In fact, they are extremely hard to overcome due to institutional complexity stemming from national variation and established international conventions (Allen 2018). Moreover, given that clarity on "autonomous operations" and their legal ramifications is limited (Karlis 2018), it is unfortunate that the whole discussion has not early included a wider array of institutional bodies in shipping. Instead, the focus revolves around makers' capacity for technological development and not the needs of shipping stakeholders. We argue herein that whether an invention (UV) will be transformed into an innovation (commercialized version of invention) and whether this innovation will add or destroy value in an industry is not only technology-dependent. Rather, it is mostly dependent on institutional, regulatory and governmental factors (Auerswald and Branscomb 2003), which explain the failure of scientific knowledge created by private firms (see Zahra et al. 2018). Therefore, unilaterally promoting makers' production abilities masks the true antecedents of value creation.

5. Makers are optimistic about the realization of UV soon. However, market-wide implications remain slightly articulated (Martin 2013). For example, what does a shift to UV mean for shipyards and their shipbuilding standards? How should ports amend their infrastructure to accommodate new cargo operations without people on board? Who will be responsible for training the personnel who will manage vessels remotely (at the so-called Shore-Control Centres; Mallam et al. 2020)?

6. How will P\&I clubs react in the case of a safety incident? While some safety challenges are known (e.g. in line with COLREG; Stenman and Öhland 2017; Naeem et al. 2012), others will inevitably emerge (e.g. related to pollution or cargo loss). Therefore, it is unclear whether UV are at least as safe and seaworthy as manned vessels.

7. Intra-organizationally, additional questions emerge: To what extent will maintenance be a critical point and how will it be performed (Porathe et al. 2014)? Should the vessel be off hire for such a task? How will aspects of cargo modularity or assemblage change? Will mega-containership units be advantaged or not? Most importantly, who is liable for the vessel's operation (Van Hooydonk 2014)? As can be surmised, these are fundamental questions, which cannot be addressed by makers alone. Rather, they require a collective response from the extended shipping community.

Therefore, challenges are technical, operational, economic, legal and safety-related apart from technological. Importantly, they are also societal. Shipping is a societyfacing field. Its centrality for citizens' well-being and its status as a major employer dictate that social approval must be actively pursued. However, one wonders whether UV will eventually benefit its makers rather than its prospective users or the society at large. A general impression is that UV projects are mostly used as marketing means 
that actively promote makers' technical sophistication (compared to their rivals), rather than convincing that UV are indeed i) feasible ii) economically viable iii) value-adding for the industry and iv) socially acceptable and beneficial. Thus, their realization seems distant to maritime scholars (Hogg and Ghosh 2016).

\section{Factors enabling the realization of UV}

It is not our purpose to nullify the feasibility potential of UV. On the contrary, we assume that UV may indeed become a reality. Therefore, our community needs to preempt the variegated challenges or welcome the opportunities associated with their emergence. Given the aforementioned impeding factors though, what is the driving force that may facilitate a shift to unmanned operations? In our view, the answer is not identified within shipping.

A catalyst for disruptive innovation is varied financial instruments (e.g. venture capitalists, stock issues, business angels), which support entrepreneurial companies that can produce innovation (Brown et al. 2009; Caselli et al. 2009; Popov and Roosenboom 2012; Bertoni and Tykvová 2015). This not only yields superior rewards but also boosts further innovation activity (Arqué-Castells 2012; Ughetto 2010; Kumar and Li 2016) especially when -as in our case- the growth potential is high (Ni et al. 2014). Furthermore, such growth potential urges financing schemes to syndicate and jointly pursue increased returns (Lehmann 2006), which accelerates the mutation of a sector. Moreover, the effect of financial markets on spurring innovation is even more profound in countries with developed economic structures (Faria and Barbosa 2014) i.e., countries where shipping companies are normally located.

Therefore, shipping is expected to face a major disruption (UV) by actors (financiers) who are not operationally involved in shipping. But, given the new contextual contingencies induced by UV, is there any possibility for non-traditional shipping players to be eventually involved? At this point, we ask: who will benefit most from a transition to UV? First, no one can safely argue that shipowners will indeed benefit. Challenges are plenty, accurate financial projections are unavailable and legalities are too conflicting to allow a robust assessment of benefits destined for ship-owners. Second, makers of UV will undoubtedly benefit since their product will be marketed to a global market of enormous potential. Who will benefit most out of all possible UV makers may be of particular competitive concern for them but not for the industry as a whole. Third, financiers will definitely benefit but it is important to delineate how. This is a main takeaway and the source of our deliberations around the future state of shipping.

On the one hand, financiers can avail of the transition to UV as an opportunistic investment i.e., to maximize financial rewards without seeking control of assets. This is a portfolio management logic, which typically injects capital to a focal industry but also leaves it in a vulnerable state when those assets migrate for a more preferential placement elsewhere (Meles et al. 2014). Hence, it is a source of major market upheavals. On the other hand, funding schemes can benefit in a strategic manner. Investment in disruptive change will take place as part of a strategic-asset seeking logic (Cui et al. 2014). Financial placements will not seek temporary rewards but rather long-term gains through the active ownership and control of strategic assets such as vessels. Therefore, 
the latter scenario implies a more fundamental challenge: is there a likely change in the ownership and governance structure of the shipping world as we know it?

\section{A barrier to entry}

Varied financial structures (e.g. KG/KS funds) or banks have always invested in shipping and historically played a critical, mediating role in the ownership of vessels by shipowners. However, there is a fundamental observation. No matter how willing financiers may be in penetrating shipping, yet they are not knowledgeable of shipping operations. This lack of knowledge is a major impediment for involvement in a strategic sense and thus, acts as a barrier to entry. Therefore, traditional shipping companies have always been relatively insulated from an unwelcome invasion of financiers. The latter care about financial rewards and thus, ownership and control of assets (vessels) remains with traditional shipping companies.

We do not deny the increased 'financialisation' of shipping. However, this has not altered the symbolic and actual management profile of the industry. Control and management of vessels is still within shipping hands and this generates value and wealth for traditional shipping companies. Therefore, in order to assess whether this is bound to change, we need to revisit the fundamentals of what shipping is about. But before doing so, we explain the method we followed for our review of relevant literature streams and their synthesis.

\section{Method}

Our study is a typical review study. It is not built on data since it relates to a future scenario that may or may not be realized. Thus, at present, we can only speculate about both the feasibility and the implications related to unmanned vessels. Given that the technical feasibility and viability of UV projects is not within the remit of this paper, we clarify our focus: our review serves the purpose of surmising industrial/organizational implications while using an a priori assumption i.e., that realization of UV will be achieved.

One can follow different means for such a review approach (for a comprehensive list of types of review see e.g. Ferrari 2015; Grant and Booth 2009; Pham et al. 2014; Paré et al. 2015). Our choice is a mixed theoretical type, which combines elements of a systematic and a narrative review. On the one hand, a systematic review seeks to search for, appraise, and synthesise studies to reveal what is known and what remains unknown in an epistemic field (Grant and Booth 2009). Uncertainty and recommendations about the future are also typical characteristics of such a systematic review with both being standard elements of our effort. On the other hand, a narrative review aims to identify what is written on a topic but without an attempt to generalize or cumulate evidence (Paré et al. 2015). This more free-floating nature of a narrative review matches well with our focus, which, as noted, remains unrealized and hence, rather elusive by default.

In the context of our study, the systematic and narrative review of the literature was conducted through the following steps: in Google Scholar, we used the following keywords: 'unmanned vessels'. This first search effort gave us our first material to review, which was mostly related to technological developments coined as 'digitalization' or 
'automation'. Consequently, we expanded our search to include 'unmanned vessels and digitalization in shipping', 'unmanned vessels and automation in shipping'. These configurations provided us with the available articles in this emerging and increasingly popular theme i.e., digital and automation advances related to unmanned vessels. As soon as we gathered a comprehensive set of papers, we reviewed those in dedicated shipping (e.g. Maritime Policy \& Management) and transportation (e.g. Transportation Reviews) journals as a priority. Through this first set of articles, we also identified additional articles (e.g. in conference proceedings; Burmeister et al. 2014 or in nonshipping journals; Huntsberger et al. 2011) which cited or were cited by those original papers.

The more expansive the dataset became through the aforementioned process, the more it indicated additional themes related to unmanned vessels beyond technology. Overall, the review of this body of literature allowed us i) to understand the variegated implications associated with unmanned vessels, which are not only technological but also operational, societal, legal, regulatory, safety-related etc. ii) to understand what is missing i.e., the literature gap that relates to existing industry structures and how these may be reconfigured following the advent of unmanned vessels. Through this review we also realized a main 'dualism' that is evident in the literature and one that is reflected in our section above: some forces enable the realization of unmanned vessels and some others impede it. Therefore, we also tried to identify i) the conditions which may eventually facilitate the emergence of such disruptive innovation ii) what this may mean for the existing industry structure.

Given our amalgamated focus on how the industry structure may be affected, we were induced to follow the same search process in the general business and management literature, too. We started our search therein with the following term: 'disruptive innovation'. Through this literature, we realized that such radical forms of innovation as unmanned vessels may facilitate the migration of value to peripheral or adjacent sectors and thus, open up the pathway for a new group of related actors to enter the scene. This key observation enabled us to review the literature on 'value migration' and 'industry dethronement'. We reviewed the studies therein while making the necessary 'translations' that are required for a meaningful transferability of insights from the general business to the shipping domain. This 'translation' process allowed us to craft relevant recommendations for practice based on an implemented scenario of unmanned vessels.

Having followed these steps, we integrated the distinct literature streams with a purpose of conducting a theoretical review i.e., one that seeks to draw on existing studies in order to transform existing knowledge into a higher order of theoretical structure (Paré et al. 2015). Our purpose was not simply to systematize and narrate what is known or not known. Rather, it was to appropriate the state of the art in order to say something wider for both scholarship and practice. In order to achieve this, we integrated our own reflection with the basic themes we described above: on the one hand, digitalization and automation advances related to unmanned vessels and on the other hand, core business themes such as value migration and industry dethronement. In this way, we contribute to the literature by framing digitalization of shipping as a phenomenon with significant implications for industry-level theorizing. Second, we surmise practical implications of this framing for existing shipping companies. In this way, 
we alert stakeholders by highlighting opportunities and sketching threats. Theoretical reviews such as ours are then valuable when "there is a lack of appropriate theories or current theories are inadequate in addressing existing research problems (Webster and Watson 2002; Paré et al. 2015, p. 198). Indeed, this is what we did to fill in the noted gap. We organized the literature on unmanned vessels under the banner of value migration (our theoretical framing) and identified implications by building around the concept of industry dethronement (our practical framing).

\section{Identifying the sources of value creation in shipping}

Shipping is valuable to the world trade because of portable assets (vessels), which can transfer large volumes of products and raw materials over significant distances and to largely inaccessible locations; all this at a transportation cost that is much more attractive compared to alternative options. A related remark is that the sources that make this value-creating process feasible are the people onboard. Certainly, UV may enhance the cost efficiency or may reduce the expenditure structure of a vessel; they may improve navigation and cargo operations following a more streamlined coordination across supply chain actors (e.g. ports, cargo owners and ship operators) or improve the environmental impact of shipping (Burmeister et al. 2014). However, for the time being, seafarers in a manned vessel largely create the value that cargo owners and final users receive.

Therefore, shipping -as the practice of moving goods from point A to point B- has historically rested on crew as those individuals who enable the operation of these portable assets. The (in)efficiency of managing this entanglement (people on a vessel at sea) is a major reason that explains the success (and failure) of shipping organizations. Thus, seafarers and their prudent management are defining elements of shipping operations (Progoulaki and Theotokas 2016). Combinatory configurations result to complex schemes due to mixed crews, different vessel types and sizes (e.g. tanker's matrix requirements), varying trade routes with specific particularities (e.g. arctic navigation) etc. At the same time, this complexity is the main reason that world trade is dependent on shipping for the safe and timely delivery of goods at point $\mathrm{B}$. If configurations were not that complex then, anyone (e.g. a bank) could potentially set up a shipping company and skilfully manage it. The needed capital would be in place and the operational complexity would simply not be there. Apparently, this is not what truly happens.

Shipping, exactly because of the complex arrangements that different people on different vessels generate, must be managed by technically knowledgeable people both ashore (e.g. operations, crew and technical managers) and onboard (officers and crew). This challenge is an inherent barrier against any entity that might wish to enter the market. Therefore, the external threat to entry is minimized. Essentially, value in shipping is created because these complex configurations amalgamate into something meaningful for clients (charterers) and because their management can be performed only by those actors (ship owners/managers) who have the requisite knowledge for the task. This inevitably raises the following question: how might those competitive dynamics change in light of the advent of UV? If manned vessels cease to exist, who will be responsible for the value that is currently created through manned shipping operations? 
Before providing our views on possible (and equally impossible) unmanned scenarios below, an important remark must be made: A reflection about those potential scenarios cannot be a-contextual. The size of the firm, the availability of capital, the intuition of the leadership team etc. are some of the factors that need to be closely considered. Even more importantly, some shipping sub-sectors, which are more directly related to to the final consumer (e.g. containers) may be more prone to such a paradigmatic UVbased disruption. Therefore, the next passages of our manuscript must be read with these caveats in mind.

\section{Possible unmanned scenarios}

Scenarios stemming from UV emergence are numerous depending on one's past experiences, present concerns and future orientation. Therefore, our scenarios below are neither conclusive nor exhaustive. They are the result of our reflection upon emergent developments while having disruptive examples from other industries in mind. The "legitimacy' of those possible scenarios is based around the centrality of seafarers for shipping operations. We put them forward as food for thought rather than as ones demanding a definite and concrete set of answers. Therefore, if seafarers, as a major source of value creation in shipping, are replaced by UV and due to technology, digitalisation and automation advances therein (e.g. in relation to navigation, manoeuvring, stability, stowage, lashing etc.) then, some inevitable questions arise. For example,

- If loading, lashing and unloading of heavy equipment or vehicles in RoRo vessels is achieved through automated mechanisms that safeguard stowage without human intervention, why wouldn't automobile manufacturers consider the possibility of owning their unmanned fleet?

- If vessel and cargo operations are largely performed at ports through automated systems and thanks to cargo modularity and assemblage then, why shouldn't a forwarding company like FedEx set up its own shipping firm?

- What is the distinct marine skill/competence that a traditional shipping firm will possess compared to e.g. a technological giant like Amazon?

- If stowage in Reefers can be accommodated without human intervention due to the standardisation of packaging processes in edible goods and the proliferation of unmanned mega-containership units, why wouldn't large food conglomerates consider the possibility of vertically integrating forward?

- If control of operations is performed ashore (through the so-called Shore Control Centers; see MUNIN) rather than at sea, what distinguishes a traditional shipping firm compared to e.g. a retailing superstore like AliBaba?

Overall, i) if traditional marine skills are no longer relevant and ii) if the high costs of crew management are not in place, what would deter cargo owners from setting up their own fleet in the context of a vertical integration strategy? In order to shed some light on those questions, some observations are warranted:

First of all, such disruption has happened in the past e.g. oil companies operated their own fleet several decades ago. Thus, the same ownership logic may re-emerge among some cargo owners due to novel contextual contingencies that may be conducive to such a re-emergence. Back then, the reasons that made oil firms outsource shipment of 
their produce to ship-owners have taken place in another context, which was (and still is) seafarer-centric. However, new realities may make past priorities come to the surface again.

Second, notwithstanding the challenge of implementation, vertical integration strategies provide many benefits to firms that pursue them such as e.g. in relation to costs of supporting assets on advanced services contracts, speed, streamlining of operational processes, effectiveness, match between capabilities and market needs, efficiency, improved quality and control mechanisms etc. (see Lajili et al. 2007; Canavari et al. 2010; Jacobides and Billinger 2006; Baines et al. 2011). Consequently, such strategies have been associated with enhanced performance and lower costs in the medium run, which are significant reasons for any firm to proceed to such action.

Third, what stands out as pertinent is that some of the aforementioned sought after benefits of vertical integration (e.g. enhancement of quality control) mirror major shortcomings that ship operators suffer from during cargo operations (handling and stowage, loading/unloading, lashing etc.) For example, an automated, unmanned vessel is expected to minimise several operational failures associated with human error e.g. poor quality stowage and unloading operations in RoRos or Reefer vessels or, overall, in relation to navigational safety.

Fourth, shipping is not an isolated transportation industry but rather one that is entirely dependent on international trade flows. Thus, one ought to consider developments outside the core of the shipping ecosystem for a more accurate understanding of future dynamics. In particular, through developments in the supply-side of transported goods, one can witness a steady pattern of market consolidation where companies essentially compete as integrated supply chains. As a result, large conglomerates (e.g. in the food industry; Canavari et al. 2010 or the automobile industry, Vickery et al. 2003) continuously punctuate the field following a series of horizontal integration strategies, mergers, acquisitions, joint ventures and other interorganisational schemes. Those mega-schemes i) are expected to have much higher scope and interest in vertically integrating forward ii) will be able to reap immediate benefits by internalising the transportation of their own produce compared to the fragmented number of small, medium or simply large producers iii) are more likely than not to have the needed capital to integrate. These consolidating, growth-oriented tendencies among cargo owners are major forces of change in the wider macro environment, which may be not shipping-specific but are certainly shipping-related.

Last but not least, firms such as big retailers, technology giants, large food conglomerates, oil companies or automobile manufacturers (to name but a few possible entrants) can arguably i) develop, internalise or access the skills associated with managing technological resources; an area they can excel in more efficient ways compared to many shipping firms ii) enjoy efficiencies stemming from shipping operations where technology -and not people any more- is the defining value-creation mechanism and cost center alike. In other words, such companies are more likely to efficiently appropriate a UV where technology is key as opposed to a small/medium-sized shipping firm, which has traditionally based its value and market 'legitimacy' on the basis of the skills of its seafaring personnel.

These are scenarios, which are inherently multifaceted and hence, uncertain in terms of their effects. Since there is causal ambiguity in terms of who is affected and how, 
there is also ambiguity about the possible outcomes. Therefore, in the context of this complexity, the only honest answer would be that no one can truly predict the feasibility potential of UV and its implications. However, for all the reasons mentioned above, UV certainly open up a possibility where sources of value creation are completely different to the ones that have traditionally characterised shipping for millennia.

This does not mean that shipping has not been confronted with similar challenges before. For example, the possible entrance of UV players is both similar and different to the trend toward separation of ownership and management. On the one hand, it is similar because groups/clusters of firms (e.g. technology operators, forwarding companies, food conglomerates, etc.) appear to be specializing in something very important in the new landscape that UV will generate. Therefore, the centrality of ship-owners is reduced in the same way that it has been reduced with the advent of ship managers. On the other hand, it is different because for the first time in history we will be witnessing the removal of an inherent, historical barrier to entry in shipping i.e., seafarers and their management. The cost of sourcing and maintaining crew (approximately $40 \%$ of a shipping firm's OPEX), the operational challenge of managing and training people onboard, as well as the complex regulatory landscape governing maritime employment (e.g. MLC and national variation in employment regulations) make crew management a technically sophisticated and highly challenging process.

Therefore, a possible removal may allow a new generation of owners to penetrate the market; owners who i) may not be well-versed into crewing operations or ii) do not historically want to assume the costs of managing a function that accounts for such a high percentage of OPEX. Nevertheless, due to the rise of UV, this lack of experience or those cost concerns will cease to be important.

This historical perspective brings us to yet another question: Is the legacy and traditional skill set of shipping firms an enabler or constraint in light of the digital transformation in shipping? We revisit this point further below. In the meantime, we explain the relevance of value migration as a key concept that reflects and theoretically frames the implications highlighted in this section.

\section{Disruptive innovation and value migration: its relevance for shipping}

Disruptive innovations tend to remove barriers to entry, facilitate entry of new players and contribute to reshaping of an industry. In turn, those new entrants stimulate demand and enable the adoption of innovation (Diekhof 2015). Therefore, disruptive innovation is not simply a catalyst or an outcome of technological change. Rather, it fundamentally changes the structure of an industry. Consequently, we approach disruption from its business model perspective i.e., a focus on how value is created or destroyed following innovation processes (Teece 2010).

More specifically, we focus on value migration, which occurs when existing key success factors become obsolete and other business models provide higher utility for customers (Slywotzky 1996). Let us 'decode' this definition. As shown before, key factors that explain value creation and hence, success in shipping revolve around the pillar of seafarers on a vessel at sea. Shipping firms have modelled their legitimacy, existence, and ultimately, value creation abilities around this schema, which is now fundamentally challenged. If seafarers are not relevant anymore and if technology becomes more valuable why would shipping company $\mathrm{X}$ be able to provide higher utility for customers? 
Utility can be translated as e.g. punctuality, lower costs, safe delivery of cargo to its destination and this may be also achieved by a non-traditional shipping entity that owns UV.

At this point, we clarify that shipping (as a function) will of course continue to exist i.e., the vast majority of goods will still be transported by sea. The critical point though is who will own and control the main assets (vessels). If marine skills are not a necessary condition for these vessels' management then, apparently, a distinctive competence of a shipping firm collapses and the entities that offer higher utility to charterers will be the ones involving technology gurus; not mariners.

Certainly, some shipping firms may adapt appropriately e.g. big ones. However, others are not expected to respond similarly to new requirements. What aggravates their incapacity is their largely small/medium and family-based nature. Notwithstanding notable exceptions, such firms tend to refrain from embracing change due to a conservative identity, rigid practices, fixed mental models as well as a fear for cannibalization and loss of hegemonic position (Kammerlander 2013). Then, there is a need for a 'heavyweight' team, which is exclusively dedicated to addressing emergent challenges (Christensen and Overdorf 2000). Often, this requires separate organizational designs as well as a new value system that is largely 'alien' to long-standing, family-based organizations. Especially in cases where disruption is both technological and economic (as is our case herein), embracing change and responding favourably requires extra entrepreneurial skills and accessing external competences (e.g. through a series of acquisitions) beyond entrenched intra-organizational wisdom (Habtay and Holmén 2014). Otherwise, incumbents who i) do not possess slack resources (e.g. capital or technological ones), ii) cannot control their environment, iii) are organizationally rigid, iv) are exposed to multiple institutional logics and conflicting regulatory environments, and v) those whose technical efficiency does not match with emergent demands, are less likely to fit into the new landscape. For such companies, mortality is engendered therein (van Mossel et al. 2018).

Such challenges are not idiosyncratic to shipping. In similar disruptive cases, companies are specifically organized and almost 'programmed' to under-invest. After all, shipping firms are good in maritime skills; not in innovation activity. Therefore, it is expected that several of them will be unable to catch up and will be forced to exit the market while being replaced by new entrants.

Overall, we argue that if shipping stakeholders ignore the lessons from adjacent industries then, they will jeopardise their own existence. Value migration may not be shipping-specific but it is highly shipping-relevant due to ever-increased digitalization. Its main features are expected to be i) a reconfiguration of the market, ii) displacement of incumbent firms iii) new players emerging and, overall, iv) change of business model. Examples of industries where digital transformation has led to value migration include other parts of the transportation sector (e.g. see Uber), hospitality (e.g. see Airbnb), education (e.g. see MOOCs), photography (e.g. see mobile phones against Fuji and Kodak films) and likely, aviation. ${ }^{2}$ Shipping is no exception to this deterministic logic and therefore, UV will induce an avalanche of ontological changes in the sector.

\footnotetext{
2"Amazon appeared to be testing air cargo operations out of Wilmington, Ohio, using leased planes". (publication title: "Amazon quietly builds its own shipping company", USA Today, 12 Jan 2016)
} 
Industry dethronement: questions that matter

The aforementioned logic culminates to a particular scenario: industry dethronement and replacement by new players. If shipping wants to maintain its status quo then, it needs to reflect on the following questions:

- Is innovation creating value? For whom?

- Which incumbents survive and prosper in light of disruptive technological change?

- What strategic decisions (e.g., organizational design and investment) are needed in light of radical industry transformation?

We put these questions forward as avenues for empirical research and policy action. First, the question of value is critical for any firm in a disrupted industry. Innovation is infused with positive connotations; it is normally portrayed as the engine of economic activity, which creates wealth and well-being. Nevertheless, this glorified image masks its dark side. Innovation -if commercially successful- may generate value for its makers but whether it will generate value for incumbents or the wider community is a different question. The answer will essentially indicate whether UV should be collectively welcomed or embraced.

In any case though, we do not aim to portray shipping firms as victims of digitalization. Apparently, some incumbents survive well enough following radical industry transformation due to e.g. accessing required resources through interorganizational collaborations (Sandström et al. 2009; Hill and Rothaermel 2003). This is a challenging exercise which will be dependent upon managers' perception and foresight, risk experience, capital structure, relational capabilities and social capital as well as brand reputation and awareness (Osiyevskyy and Dewald 2015). At the same time though, a particular threat is noted for laggard firms, which do not manage to adapt to new requirements (Aghion et al. 2009). Thus, we discuss implications and some ways forward.

\section{Discussion}

What happens when a new business model provides enhanced value to customers and, at the same time, it is the amalgamated outcome of externally induced technological innovation processes? We argue that disruptive change (Christensen et al. 2015) that is externally induced (i.e., spearheaded by actors outside the core of the industry) leads to value migration (Slywotzky 1996; Rindova and Kotha 2001) and ultimately, to industry dethronement (Smith et al. 2001). We applied this line of reasoning in maritime business; an industry, which operates i) under rigid standards of long-established market leadership but ii) is confronted with unprecedented levels of disruption.

These two points are critical. Up until now, industry dethronement (i.e., the loss of market leadership) has been investigated from the perspective of market leader and challengers i.e., as an intra-industrial competitive duality. The competitive aggressiveness of challengers and/or the rigidity of leaders' response is what induces market erosion and shift to a new regime (Smith et al. 2001). Our paper cautions that value migration and industry dethronement has extra-industrial antecedents, too which need careful consideration by incumbents. Otherwise, a myopic and esoteric understanding will simply facilitate the entry of external, non-core-shipping players. 
We structured our arguments around UV; a technological development, which fundamentally changes the nature of how shipping operates for centuries. Seafarers' selection, recruitment, placement, motivation, training etc. are highly idiosyncratic and challenging tasks, which at the same time, explain the success or failure potential of every shipping firm. Those seafarers are practically the resources, which control and manage a shipping firm's most valuable asset (its vessels). UV will render these human resources obsolete essentially deconstructing one of the traditional sources of value creation in shipping.

On the one hand, this is unfortunate since technological developments routinely affect certain parts of employment across industries. For example, satellite telecommunications have made radio officers in merchant shipping redundant. Therefore, unemployment is expected to be increased in several countries where merchant shipping is a vital source of employment and income (both family and state-wise). The latter is mostly the case in developing economies, which makes the whole discussion around the future of maritime employability even more critical.

On the other hand, positive consequences are also expected. For example, UV generate the possibility of a more streamlined supply chain. The integration of ports, operators and technological equipment promises greater punctuality, less operational failures and smoother coordination of the sub-activities that make up the totality of shipping operations. This is expected to translate into tangible benefits such as e.g. lower costs thus, making UV a highly attractive scenario for multiple stakeholders.

Notwithstanding the pros and cons of a potential shift to UV, this study notes a very particular characteristic that merits a wider discussion: traditional shipping firms are good in managing a vessel with people at sea. They are not 'programmed' to invest in disruptive innovation through e.g. continuous morphing (Rindova and Kotha 2001). This would shake out a very conservative industry where incumbents have historically availed of a stagnant status quo in terms of market leadership. Therefore, any change does not accord with their 'cultural' make-up simply because there was never the need to adapt to such a disruptive extent. On the contrary, non-shipping firms such as technology giants have not only an active interest but also the possibility to build or access the critical resources that will explain success or failure in the new, autonomous landscape that UV will generate.

\section{Managerial implications}

This paper adopts the perspective of the incumbent shipping firm. Thus, the suggestions for practice have this particular stakeholder in mind. Nevertheless, we do not negate the multiple implications for a variety of other shipping stakeholders, too. Overall, therefore, shipping firms may respond in two broad ways: i) either resist through a repertoire of heterogeneous responses or ii) the new complex regime will need to be reflected intra-organizationally through specific bold decisions.

- With regards to the former (resistance to UV), collective mobilisation against the realization of UV may be initiated by a substantial number of incumbent firms (see Adner and Snow 2010). Since the new regime appears unwieldy and overwhelming for many of those firms (especially small/medium-sized firms), initiatives may be 
pursued, which actively resist against the establishment of an unmanned future (e.g. due to COLREG-related or wider safety concerns). This will require the engagement and collaboration of e.g. unions, maritime organizations, insurers, port agents and other shipping stakeholders. If this collective mobilization is achieved, it can become a serious impediment to the realization of UV. Thus, instead of preparing for an unmanned future, firms can also actively resist against its emergence.

- With regards to the latter (accepting UV), the implications are strategic in nature and require firms to either amend their organizing structure or enhance their engagement with another relational network. Conventional organizational structures will need to be revisited, new roles may need to be in place (e.g. Chief Technology Officers) and funds may be redirected for investment elsewhere. Such intra-organizational responses may be necessary but engender certain challenges. Often, firms confronted with such disruptive regimes tend to either view the disruption as a threat (resulting to overreaction and commitment of too many resources too quickly) or see it as an opportunity (resulting to committing insufficient and non-fitting resources to its exploitation; Gilbert and Bower 2002).

Therefore, the first practical suggestion in relation to response (ii) above is the following: the development of another kind of technological awareness and 'sensitivity' when it comes to digitalization and automation advances. In other words, firms need to keep abreast of technological developments and anticipate likely changes depending on the scenarios explained before. In addition to introducing a new hierarchical position such as a Chief Technology Officer, they should also seek to participate in relevant events and fora discussing developments related to automation, they may start a collaboration with the research departments of technology-oriented universities or they may establish partnerships and alliances with (non)maritime technology firms, which can help them access or build those technological resources and skills.

The second suggestion is that firms need to establish a closer link with funding bodies and financial instruments. An unmanned future may require a huge commitment of financial resources and incumbents' own funds may be insufficient for the transition to a new regime. Thus, the abovementioned relational network should include financial bodies, which can be convinced about the sophistication and competence of the incumbent shipping firm. In turn, such bodies will be willing to financially support necessary shifts and changes. Without this extraorganizational support, many shipping firms (usually smaller ones) are expected to lag behind in terms of needed capital and financial resources.

The third suggestion is related to hybridity and morphing i.e., a mutation of the identity of the company into something else or something in addition to what already is. Shipping firms may choose to diversify into becoming technologyoriented companies through investment in e.g. software and hardware products for maritime purposes in addition to normal shipping operations. As Rindova and Kotha (2001) note, such related morphing will gradually build necessary skills in a complementary fashion while enriching the overall property and knowledge resources of the diversified shipping firm. In this way, it will be better prepared for upcoming scenarios that relate to technological applications in maritime transportation. 


\section{Conclusion}

Digital transformation is omnipresent. Technological advances routinely penetrate markets and reconfigure the way business is conducted. Nevertheless, not all sectors are equally conducive to disruptive change. Some markets are more conservative than others in terms of embracing it and as such, externally induced innovations challenge the very ontological identity of an industry. The impact is of particular value since traditional shipping firms enjoy phenomenal rewards for decades or even centuries. Within this context, the innovations that have historically characterized shipping (e.g. steam engine) may have challenged the abilities of incumbents or have called for revitalization of their skills. However, they have never posed any existential threat to the ownership and governance structure of the industry as we know it.

However, cautioning about the advent of technology does not imply that we are antitechnology evangelists. Technology has offered unique benefits to our industry and has been the primary means for quality enhancement. It has contributed not only to operational matters but also to crew welfare and as such it has advanced shipping both in terms of market efficiency and social responsibility. However, technology is creatively destructive in its pure Schumpeterian sense, too i.e., its novelty ramifications are not unproblematic. The emergence of novelty challenges the status quo; mobilises new actors and re-sketches industry boundaries. Therefore, while its benefits should be always welcomed, a balanced treatment warrants a closer look to its transformative potential; a potential, which has the magnitude to fundamentally shake out an industry and alter its identity. In essence, technological advances force us to fundamentally rethink who will sooner or later own the assets (vessels) which are 'responsible' for the delivery of $90 \%$ of the world's trade.

Abbreviation

UV: Unmanned vessels

Acknowledgements

Not applicable.

\section{Authors' contributions}

KP formulated the idea and its development. GG provided info about the current stance of the shipping world (e.g. shipowners) towards unmanned vessels and suggested ways of responding. GT provided info about responses from the institutional bodies governing shipping. EP assisted KP in integrating concerns associated with unmanned vessels with the relevant business literature on value migration and industry dethronement. The author(s) read and approved the final manuscript.

Authors' information

KP is an academic interested in the intersection of shipping with broader business and management studies. GG is a shipping entrepreneur with close links to the shipping world since the 1970s. GT is a former Chairman of a key institutional body in international shipping. EP is a senior executive in a leading management firm in shipping.

Funding

No funding.

Availability of data and materials

Not applicable.

Competing interests

No competing interest.

Author details

${ }^{1}$ Middlesex University, London, UK. ${ }^{2}$ Epsilon Hellas, Limassol, Cyprus. ${ }^{3}$ International Maritime Employers' Council (IMEC), London, UK. 
Received: 6 December 2019 Accepted: 6 May 2020

Published online: 22 May 2020

\section{References}

Adner R, Snow D (2010) Old technology responses to new technology threats: demand heterogeneity and technology retreats. Ind Corp Change 19(5):1655-1675

Aghion P, Blundell R, Griffith R, Howitt P, Prantl S (2009) The effects of entry on incumbent innovation and productivity. The Rev Econ Stat 91(1):20-32

Allen CH (2018) Determining the legal status of unmanned maritime vehicles: formalism vs functionalism. J Mar Law Comm 49(4):477

Arqué-Castells P (2012) How venture capitalists spur invention in Spain: evidence from patent trajectories. Res Policy 41(5): $897-912$

Auerswald PE, Branscomb LM (2003) Valleys of death and Darwinian seas: financing the invention to innovation transition in the United States. J Tech Trans 28(3):227-239

Baines T, Lightfoot H, Smart P (2011) Servitization within manufacturing: exploring the provision of advanced services and their impact on vertical integration. J Manuf Tech Manag 22(7):947-954

Bertoni F, Tykvová T (2015) Does governmental venture capital spur invention and innovation? Evidence from young European biotech companies. Res Policy 44(4):925-935

Brown JR, Fazzari SM, Petersen BC (2009) Financing innovation and growth: cash flow, external equity, and the 1990s R\&D boom. J of Fin 64(1):151-185

Burmeister HC, Bruhn W, Rødseth ØJ, Porathe T (2014) Transport Research Arena (TRA) 5th Conference: Transport Solutions from Research to Deployment. TRA, Paris

Canavari M, Centonze R, Hingley M, Spadoni R (2010) Traceability as part of competitive strategy in the fruit supply chain. Brit Food J 112(2):171-186

Caselli S, Gatti S, Perrini F (2009) Are venture capitalists a catalyst for innovation? Europ Fin Manag 15(1):92-111

Christensen CM, Overdorf M (2000) Meeting the challenge of disruptive change. Harvard Bus Rev 78(2):66-77

Christensen CM, Raynor ME, McDonald R (2015) Disruptive innovation. Harvard Bus Rev 93(12):44-53

Cui L, Meyer KE, Hu HW (2014) What drives firms' intent to seek strategic assets by foreign direct investment? A study of emerging economy firms. J of World Bus 49(4):488-501

D'Agostini E, Ryoo DK, Jo SH (2017) A study on Korean seafarer's perceptions towards unmanned ships. J of Navig and Port Res 41(6):381-388

Diekhof J (2015) Do entrants increase incumbents' innovation activity? Escaping the lock-in, stimulating technological change and the transition towards environmentally friendly vehicles. J of Innov Econ \& Manag 1:101-137

Faria AP, Barbosa N (2014) Does venture capital really foster innovation? Econ Lett 122(2):129-131

Ferrari R (2015) Writing narrative style literature reviews. Med Writing 24:230-235

Fruth M, Teuteberg F (2017) Digitization in maritime logistics—what is there and what is missing? Cogent Business \& Manag 4(1):1411066

Ghaderi H (2019) Autonomous technologies in short sea shipping: trends, feasibility and implications. Transp Rev 39(1):152173

Gilbert C, Bower JL (2002) Disruptive change. When trying harder is part of the problem. Harvard Bus Rev 80(5):94-101

Grant MJ, Booth A (2009) A typology of reviews: an analysis of 14 review types and associated methodologies. Health Inform Libr J 26:91-108

Habtay SR, Holmén M (2014) Incumbents' responses to disruptive business model innovation: the moderating role of technology vs. market-driven innovation. Intern J Entr and Innov Manag 18(4):289-309

Hill CW, Rothaermel FT (2003) The performance of incumbent firms in the face of radical technological innovation. Acad Manag Rev 28(2):257-274

Hogg T, Ghosh S (2016) Autonomous merchant vessels: examination of factors that impact the effective implementation of unmanned ships. Austr J Mar Ocean Aff 8(3):206-222

Huntsberger T, Aghazarian H, Howard A, Trotz DC (2011) Stereo vision-based navigation for autonomous surface vessels. J Field Robotics 28(1):3-18

Jacobides MG, Billinger S (2006) Designing the boundaries of the firm: from "make, buy, or ally" to the dynamic benefits of vertical architecture. Org Sci 17(2):249-261

Kammerlander N (2013) Organizational Adaptation to Discontinuous Technological Change. The Effects of Family Influence and Organizational Identity. Familienunternehmen und KMU. Gabler Verlag, Boston. p. XVIII, 334. https://doi.org/10.1007/ 978-3-658-01315-8.

Karlis T (2018) Maritime law issues related to the operation of unmanned autonomous cargo ships. WMU J Mar Aff 17(1):119128

Kretschmann L, Burmeister HC, Jahn C (2017) Analyzing the economic benefit of unmanned autonomous ships: an exploratory cost-comparison between an autonomous and a conventional bulk carrier. Res Transportation Bus Manag 25: $76-86$

Kumar P, Li D (2016) Capital investment, innovative capacity, and stock returns. J Fin 71(5):2059-2094

Kuo SY, Lin PC, Lu CS (2017) The effects of dynamic capabilities, service capabilities, competitive advantage, and organizational performance in container shipping. Transp Res Part A: Policy Practice 95:356-371

Lajili K, Madunic M, Mahoney J (2007) Testing organizational economics theories of vertical integration. In: Ketchen D, Bergh $D$ (eds) Research methodology in strategy and management (research methodology in strategy and management, Vol. 4). Emerald Group Publishing Limited, Bingley, pp 343-368

Lambrou M, Watanabe D, lida J (2019) Shipping digitalization management: conceptualization, typology and antecedents. J Ship Trade 4(1):11

Lee CB, Wan J, Shi W, Li K (2014) A cross-country study of competitiveness of the shipping industry. Transp Policy 35:366-376 Lehmann EE (2006) Does venture capital syndication spur employment growth and shareholder value? Evidence from German IPO data. Small Bus Econ 26(5):455-464 
Lochner M, Duenser A, Lutzhoft M, Brooks B, Rozado D (2018) Analysis of maritime team workload and communication dynamics in standard and emergency scenarios. J Ship Trade 3(1):2

Mallam SC, Nazir S, Sharma A (2020) The human element in future Maritime Operations-perceived impact of autonomous shipping. Ergonomics, 63:(3):334-345, https://doi.org/10.1080/00140139.2019.1659995.

Martin AY (2013) Unmanned maritime vehicles: technology evolution and implications. Mar Tech Soc J 47(5):72-83

Meles A, Monferrà S, Verdoliva V (2014) Do the effects of private equity investments on firm performance persist over time? App Fin Econ 24(3):203-218

Milakis D (2019) Long-term implications of automated vehicles: an introduction. Transp Rev 39:1-8

Mlimbila J, Mbamba UOL (2018) The role of information systems usage in enhancing port logistics performance: evidence from the Dar Es Salaam port, Tanzania. J Ship Trade 3(1):1-20

Naeem W, Irwin GW (2010) An automatic collision avoidance strategy for unmanned surface vehicles. In: Life system modeling and intelligent computing. Springer, Berlin, Heidelberg, pp 184-191

Naeem W, Irwin GW, Yang A (2012) COLREGs-based collision avoidance strategies for unmanned surface vehicles. Mechatronics 22(6):669-678

Ni H, Luan T, Cao Y, Finlay DC (2014) Can venture capital trigger innovation? New evidence from China. Int J Tech Manag 65(1-4):189-214

Osiyevskyy O, Dewald J (2015) Explorative versus exploitative business model change: the cognitive antecedents of firm-level responses to disruptive innovation. Strat Entr J 9(1):58-78

Paré G, Trudel MC, Jaana M, Kitsiou S (2015) Synthesizing information systems knowledge: a typology of literature reviews. Inform Manag 52:183-199

Pham MT, Rajić A, Greig JD, Sargeant JM, Papadopoulos A, McEwen SA (2014) A scoping review of scoping reviews: advancing the approach and enhancing the consistency. Res Synth Methods 5:371-385

Popov A, Roosenboom P (2012) Venture capital and patented innovation: evidence from Europe. Econ Pol 27(71):447-482

Porathe T (2014) Remote, onitoring and control of unmanned vessels-the MUNIN shore control Centre. In: Proceedings of the 13th international conference on computer applications and information Technology in the Maritime Industries, pp 460-467

Porathe T, Prison J, Man Y (2014) Situation awareness in remote control centres for unmanned ships. In: Proceedings of Human Factors in Ship Design \& Operation, 2014, London, p. 93-101

Progoulaki M, Theotokas I (2016) Managing culturally diverse maritime human resources as a shipping company's core competency. Mar Pol Manag 43(7):860-873

Rindova VP, Kotha S (2001) Continuous "morphing": competing through dynamic capabilities, form, and function. Acad Manag J 44(6):1263-1280

Rødseth ØJ, Burmeister HC (2015) Risk assessment for an unmanned merchant ship. Trans Nav, Intern J Mar Navig Saf Sea Transp 9(3):357-64

Sandström C, Magnusson M, Jörnmark J (2009) Exploring factors influencing incumbents' response to disruptive innovation. Creat Innov Manag 18(1):8-15

Slywotzky AJ (1996) Value migration: how to think several moves ahead of the competition. Boston: Harvard Business Press

Smith KG, Ferrier WJ, Grimm CM (2001) King of the hill: dethroning the industry leader. Acad Manag Exec 15(2):59-70

Stenman A, Öhland S (2017) Interaction between unmanned vessels and colregs

Teece DJ (2010) Business models, business strategy and innovation. Long Ran Plan 43(2):172-194

Ughetto E (2010) Assessing the contribution to innovation of private equity investors: a study on European buyouts. Res Pol 39(1):126-140

Van Hooydonk E (2014) The law of unmanned merchant shipping-an exploration. J Intern Marit Law 20(3):403-423

van Mossel A, van Rijnsoever FJ, Hekkert MP (2018) Navigators through the storm: a review of organization theories and the behavior of incumbent firms during transitions. Envir Innov Societ Trans 26:44-63

Vanelslander T, Sys C, Lam JS, Ferrari C, Roumboutsos A, Acciaro M, Macário R, Giuliano GA (2019) Serving innovation typology: mapping port-related innovations. Transp Rev 13:1-9

Vickery SK, Jayaram J, Droge C, Calantone R (2003) The effects of an integrative supply chain strategy on customer service and financial performance: an analysis of direct versus indirect relationships. J Oper Manag 21(5):523-539

Webster J, Watson RT (2002) Analyzing the past to prepare for the future: writing a literature review. MIS Quart 26:13-23

Wróbel K, Montewka J, Kujala P (2017) Towards the assessment of potential impact of unmanned vessels on maritime transportation safety. Rel Eng Syst Saf 165:155-169

Yang D, Wu L, Wang S, Jia H, Li KX (2019) How big data enriches maritime research-a critical review of automatic identification system (AIS) data applications. Transp Rev 39(6):755-773

Zahra SA, Kaul A, Bolívar-Ramos MT (2018) Why corporate science commercialization fails: integrating diverse perspectives. Acad Manag Persp 32(1):156-176

\section{Publisher's Note}

Springer Nature remains neutral with regard to jurisdictional claims in published maps and institutional affiliations. 